ИЗВЕСТИЯ АКАДЕМИИ НАУК ЭСТОНСКОП ССР. ТОМ 25 ХИМИЯ * ГЕОЛОГИЯ. 1976, №2 2

\title{
НОВЫЕ ВИДЫ АКРИТАРХ КЕМБРИЯ ПРИБАЛТИКИ
}

В последние годы много внимания уделяется исследованию акритарх - типичных для кембрийских отложений Прибалтики микрофоссилий. Другие виды органических остатков кембрия этого региона не имеют столь большого значения для стратиграфии и столь широкого распространения, как акритархи. До их изучения в Прибалтике многие толщи кембрия считались «немыми» и не имели точно определенного возраста.

Основные сведения по стратиграфическому распространению акритарх кембрия Прибалтики изложены в работах А. И. Фридрихсоне (1971), Н. А. Волковой $(1968,1973)$, А. П. Биркиса и др. (1970), Н. И. Умновой и Е. К. Фандерфлит (1971) и авторов (Янкаускас, 1972, 1974; Янкаускас, Пости, 1973). В результате этих исследований в нижнем кембрии Прибалтики установлено пять, а в среднем - два комплекса акритарх, сменяющих друг друга по разрезу и позволяющих расчленить весь разрез на семь горизонтов (снизу вверх): ровенский, лонтоваский, люкатиский, вергальский, раусвеский, кибартайский и дейменский.

Дальнейшие исследования показали, что указанные комплексы акритарх могут быть пополнены многими новыми видами. Приведем здесь описания и изображения десяти из них.

Tasmanites piritaensis Posti et Jank. характерен только для люкатиского горизонта, Lophominuscula verruculata Jank. - только для вергальского, Micrhystridium oligum Jank. - только для раусвеского и Microconcentrica deimenica Jank. - только для дейменского. Пять видов: Baltisphaeridium acerosum Jank. et Posti, B. strigosum Jank., Micrhystridium heterospinosum Jank., Cymatiosphaera capsulara Jank. и Leiosphaeridia bicrura Jank. типичны для вергальского и раусвеского, а Cymatiosphaera radiata Jank. - для вергальского, раусвеского и частично кибартайского горизонтов,

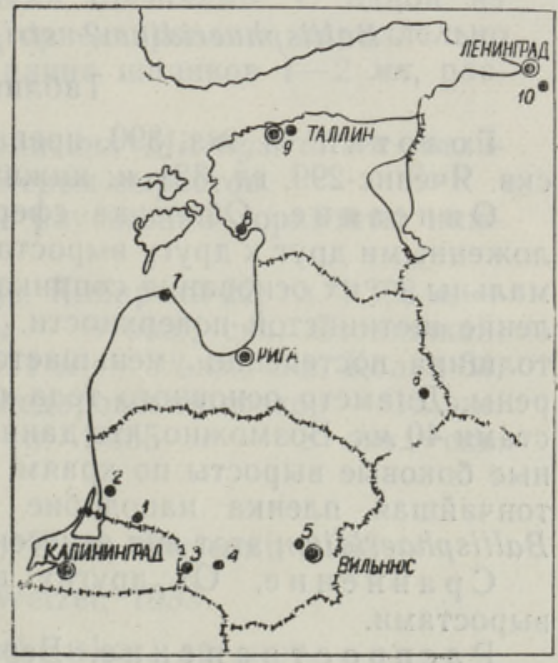

Расположение скважин и обнажений: 1 - скв. Стонишкяй (=Советская); 2 - скв. Гаргждай-8; 3 - скв. Кибартай-22 (и 30$) ; 4-$ скв. Саснава-6; 5 - скв. Ячёнис- $299 ; 6-$ скв. Лудза- $15 ; 7$ - скв. Колка-54; 8 - скв. Селисте-173; 9 - обн. Козе-Люкати; 10 - обн. на р. Ижора в Ленинградской области. 
Пробы для выделения акритарх отобраны авторами из обнажений и из керна буровых скважин (рисунок). Препараты описанных видов акритарх хранятся в коллекциях ЛитНИГРИ.

\section{Группа Acritarha Evitt, 1963}

Подгруппа Acanthomorphitae Downie, Evitt, Sarjeant, 1963 Род Baltisphaeridium Eisenack, 1958

Baltisphaeridium acerosum ${ }^{1}$ Jankauskas et Posti, sp. nov. Таблица, фиг. $5-7,12$

Голо ти п - экз. 388, препарат № 15-25-696/4; фиг. 5; ЛатвССР, скв. Лудза-15, гл. 696 м; нижний кембрий, раусвеский горизонт.

О пи с ание. Оболочка сферическая, тонкостенная, светло-желтая. Диаметр оболочки 25-40 мк, толщина ее стенки $0,3-0,5$ мк. На поверхности оболочки густо расположены мелкие темные бугорки размером $0,3-0,4 \mu \kappa$, расстояния между ними от $1-1,5$ до $2 \mu \kappa$. От вершинок бугорков отходят тонкие узкоконические шипики длиной до 1 мк. Толщина шипиков постепенно уменьшается от основания, их кончики либо заострены, либо несут булавовидные утолщения.

C р а внение. От морфологически близкого B. dubium Volk. отличается более грубым строением, наличием бугорка в основании шипиков и нередко утолщений на кончиках шипиков.

Р асп ространени е. Вергальский и раусвеский горизонты нижнего кембрия Прибалтики.

М а те р и а л. Вергальский горизонт: скв. Кибартай-22, гл. 1388 м 5 экз. Раусвеский горизонт: скв. Селисте-173, гл. 489 м 20 экз.; гл. $493 \mu-9$ экз.; скв. Лудза-15, гл. $696 \mu-$ более 20 экз. и др.

\section{Baltisphaeridium? strigosum ${ }^{2}$ Jankauskas, sp. nov.}

$$
\text { Таблица, фиг. } 8,14
$$

Г оло тип - экз. 390, препарат № 15-30-321/10; фиг. 14; ЛитССР, скв. Ячёнис-299, гл. 321 м; нижний кембрий, вергальский горизонт.

О пи сание. Оболочка сферическая, густо покрыта близко расположенными друг к другу выростами. Расстояния между выростами минимальны - их основания соприкасаются друг с другом, создавая впечатление щетинистой поверхности. По форме выросты ресничковидные, их толщина постепенно уменьшается от основания, кончики всегда заострены. Диаметр основного тела около 30 мк, а диаметр вместе с выростами 40 мк. Возможно, что данная форма сплющена и имеет более длинные боковые выросты по краям, между которыми может присутствовать тончайшая пленка наподобие оторочки птероспермопсисов. $\mathrm{K}$ роду Baltisphaeridium этот вид отнесен условно.

С равнение. От других видов рода отличается очень густыми выростами.

Р аспростр анение. Вергальский и раусвеский горизонты нижнего кембрия Прибалтики.

М а тери ал. Вергальский горизонт: скв. Кибартай-22, гл. 1388$1383 \mu-11$ экз.; скв. Стонишкяй, гл. 2109 м - 3 экз.; скв. Ячёнис-299, гл. $321 \mu-6$ экз. Раусвеский горизонт: скв. Селисте-173, гл. $493 \mu-$

1 Oт acerosus (лат.) - игольчатый.

2 От strigosus (лат.) - щетинистый. 
1 экз.; скв. Кибартай-22, гл. 1355 м - 3 экз.; скв. Лудза-15, гл. 696 м 14 экз. и др.

Род Micrhystridium Deflandre, 1937

Micrhystridium oligum ${ }^{3}$ Jankauskas, sp. nov.

Таблица, фиг. $10,13,15,16,20$

Голотип - экз. 393, препарат № 15-4-1355/2; фиг. 15; ЛитССР, скв. Кибартай-22, гл. 1355 м; нижний кембрий, раусвеский горизонт.

О п и сани е. Оболочка мелкая, тонкостенная, покрыта малочисленными короткими, утолщенными на кончиках выростами. Единичные выросты на кончиках разветвляются. Диаметр оболочки $7-8$ мк; число выростов (по контуру) 15-17, их длина $1-1,5 \mu \kappa$, ширина $0,2-0,25 м \kappa$.

C р а в н ен и е. От наиболее близкого M. notatum Volk. из более молодых слоев (средний кембрий) отличается меньшими размерами, более короткими и редкими, иногда разветвляющимися выростами.

Р а с п р ост р ан ен и е. Раусвеский горизонт нижнего кембрия Прибалтики.

М а те р и а л. Скв. Кибартай-22, гл. $1355 \mu-$ обильно, гл. 1347 м обильно, гл. $1334 \mu-$ часто.

\section{Micrhystridium heterospinosum ${ }^{4}$ Jankauskas, sp. nov.}

Таблица, фиг. 17

Голлот и п - экз. 401, препарат № 15-4-1383/6; фиг. 17; ЛитССР, скв. Кибартай-22, гл. 1383 м; нижний кембрий, вергальский горизонт.

О п и с н и е. Оболочка мелкая, тонкостенная, обычно сферическая, реже дискоидальная, покрыта мелкими шипиками неодинаковой длины и разной формы - более длинными с заостренными кончиками (наподобие колючек) и более короткими с тупыми кончиками. С одной из сторон выросты могут быть удлинены и ориентированы параллельно друг другу. Диаметр оболочки 8-10 $м \kappa$, длина шипиков $1-2$ мк, расстояния между ними $1-2$ мк.

С р а в нение. От других видов кембрийских Micrhystridium отличается разной формой и неодинаковым размером выростов.

$\mathrm{P}$ a сп ространени е. Вергальский и раусвеский горизонты нижнего кембрия Прибалтики.

М а те р и а л. Вергальский горизонт: скв. Кибартай-22, гл. 1388 м 10 экз.; гл. $1383 \mu-14$ экз.; гл. 1381 м 13 экз.; скв. Стонишкяй, гл. $2109 \mu-9$ экз.; скв. Ячёнис-299, гл. 321 м 3 экз.; скв. Колка-54, гл. $824 \mu-4$ экз.; р. Ижора, обн. у пос. Федоровский совхоз - 15 экз. Раусвеский горизонт: скв. Кибартай-22, гл. $1355 \mu-8$ экз.; скв. Лудза-15, гл. $696 м-3$ экз.

\section{Подгруппа Hercomorphitae Downie, Evitt, Sarjeant, 1963}

\section{Род Cymatiosphaera O. Wetzel, 1933}

Cymatiosphaera capsulara ${ }^{5}$ Jankauskas, sp. nov.

$$
\text { Таблица, фиг. 1, } 4
$$

Г ол о т и п - экз. 384, препарат № 15-25-696/4; фиг. 4; ЛатвССР, скв. Лудза-15, гл. 696 м; нижний кембрий, раусвеский горизонт.

3 Oт oligus (лат.) - малый.

4 От heterospinosus (лат.) - имеющий разные мелкие колючки.

5 От capsularis (лат.) - коробчатый. 
О пи с ан и е. Оболочка тонкостенная, субкубической формы с высокими гребнями по граням, бледно-желтая. Диаметр оболочки $30-45 м \kappa$, высота гребней 5-8 $м \kappa$, толщина стенки до 5 мк. формой.

С равнение. От других видов рода отличается субкубической

Р аспространение. Вергальский и раусвеский горизонты нижнего кембрия Прибалтики.

М а те р и ал. Вергальский горизонт: скв. Кибартай-22, гл. 1388 м 4 экз.; гл. 1383 м 4 экз. Раусвеский горизонт: скв. Лудза-15, гл. $696 \mu-$ 4 эКЗ.

\section{Cymatiosphaera radiata ${ }^{6}$ Jankauskas, sp. nov.}

Таблица, фиг. 2, 3

Г ол о ти п - экз. 386, препарат № 15-4-1355/4; фиг. 3 ; ЛитССР, скв. Кибартай-22, тл. 1355 м; нижний кембрий, раусвеский горизонт.

О пис а н е. Оболочка полиэдрической формы. На гранях распола-

6 Oт radiatus (лат.) - лучистый.

Фиг. 1, 4. Cymatiosphaera capsulara Jank., sp. nov. 4 - голотип, № 15-25-696/4, экз. 384 ; Латвия, скв. Лудза- 15 , гл. 696 м, лакайская свита, раусвеский горизонт, $\times 1000$. 1 - № 15-4-1388/6, экз. 385; Литва, скв. Кибартай-22, гл. 1388 м, гегеская свита, вергальский горизонт, $\times 1000$.

Фиг. 2, 3. Cymatiosphaera radiato Jank., sp. nov. 3 - голотип, № 15-4-1355/4, экз. 386; Литва, скв. Кибартай-22, гл. 1355 м, вирбальская свита, раусвеский горизонт, $\times 1000$. 2 - № 15-40/8-2036, экз. 387; Литва, скв. Гаргждай-8, гл. 2036 м, кибартайская свита (=горизонт),$\times 1000$.

Фиг, 5, 6, 7, 12. Baltisphaeridium acerosum Jank. et Posti, sp. nov. 5 - голотип, № 15-25-696/4, эКз. 388: Латвия, скв. Лудза-15, гл. 696 м, лакайская свита, раусвеский горизонт, $\times 1000$. 6 и $7-$ экз. 389 и 404 из того же местообитания, $\times 1000$ и $\times 630$; 12 - экз. 400, там же, $\times 1000$.

Фиг. 8, 14. Baltisphaeridium strigosum Jank.., sp. nov. 14 - голотип, № 15-30-321/10, экз. 390; Литва. скв. Яччёнис-299. гл. 321 м, лакайская свита, вергальский горизонт, $\times 1000.8$ - № 15-25-696/4, экз. 391; Латвия, скв. Лудза-15, гл. 696 м, лакайская свита, раусвеский горизонт, $\times 1000$.

Фиг. 9. Microconcentrica deimenica Jank., sp. nov. Голотип, № 15-4-329-В, экз. 392; Литва, скв. Кибартай-30, гл. 1268,5 м, дейменская серия, средний кембрий, $\times 1000$.

Фиг. 10, 13, 15, 16, 20. Micrhystridium oligum Jank., sp. nov. 15 - голотип, № 15-4-1355/2, экз. 393; Литва, скв. Кибартай-22, гл. 1355 м, вирбальская свита, раусвеский горизонт, $\times 1000,10,13,16$ и $20-$ экз. $394-397$ из того же местообитания, $\times 1000$.

Фиг. 11, 21. Leiosphaeridia bicrura Jank., sp. nov. 11 - голотип, № 15-30-312/1, экз. 398; Литва, скв. Ячёнис-299, гл. 312 м, лакайская свита, раусвеский горизонт, $\times 1000,21-$ экз. 399 из того же местообитания, $\times 630$.

Фиг. 17. Micrhystridium heterospinosum Jank., sp. nov. Голотип, № 15-4-1383/6, экз. 401; Литва, скв. Кнбартай-22, гл. 1383 м, гегеская свита, вергальский горизонт, $\times 1000$.

Фиг. 18. Tasmanites piritaensis Posti et Jank., sp. nov. Голотип, № 15-19-29-A, экз. 402; Эстония, р. Пирита, обн, Козе-Люкати, тискреская свита, какумягиская пачка, люкатиский горизонт, $\times 500$.

Фиг. 19. Lophominuscula verruculata Jank., sp. nov. Голотип, № 15-4-1383/6, экз. 403; Литва, скв. Кибартай-22, гл. 1383 м, гегеская свита, вергальский горизонт, $\times 1000$. 

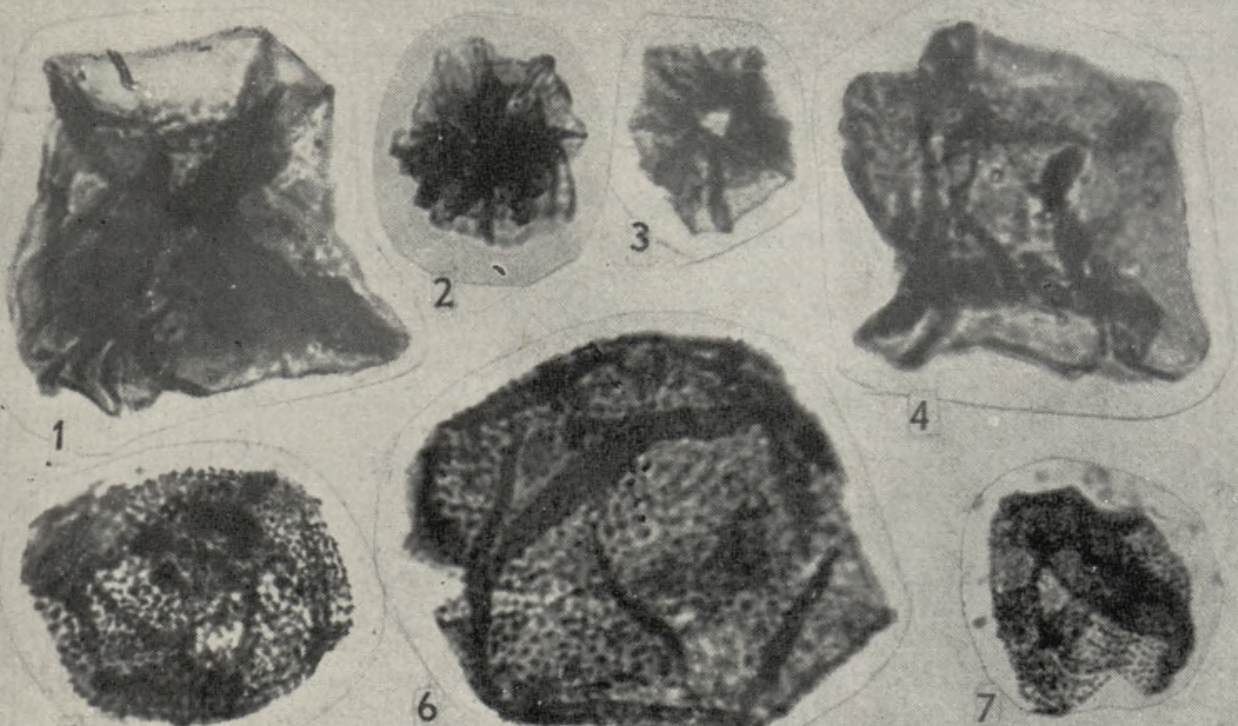

5

6

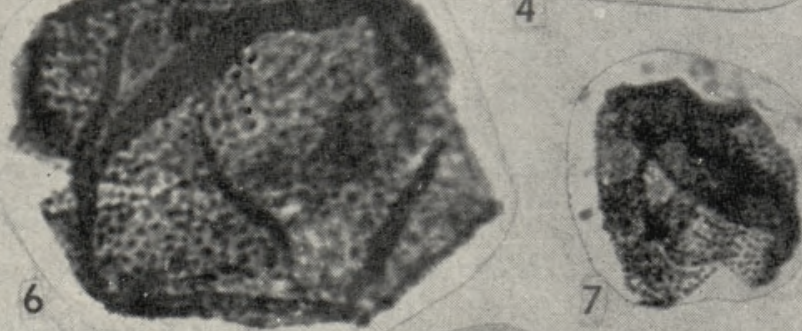

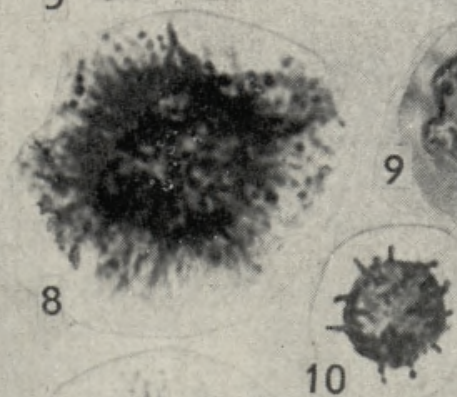

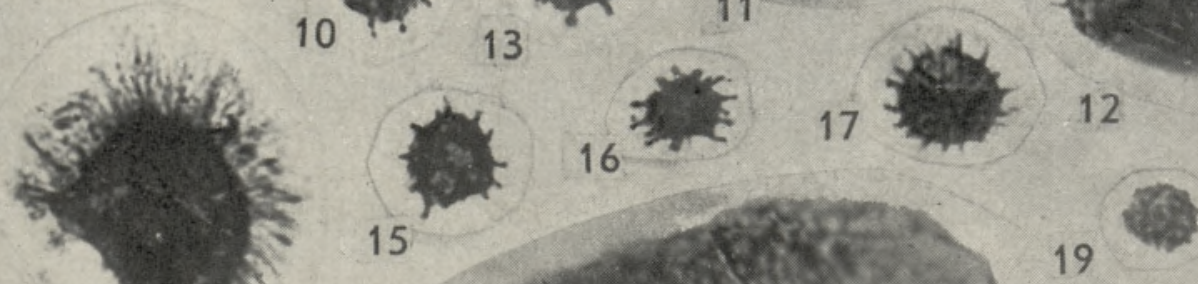

13
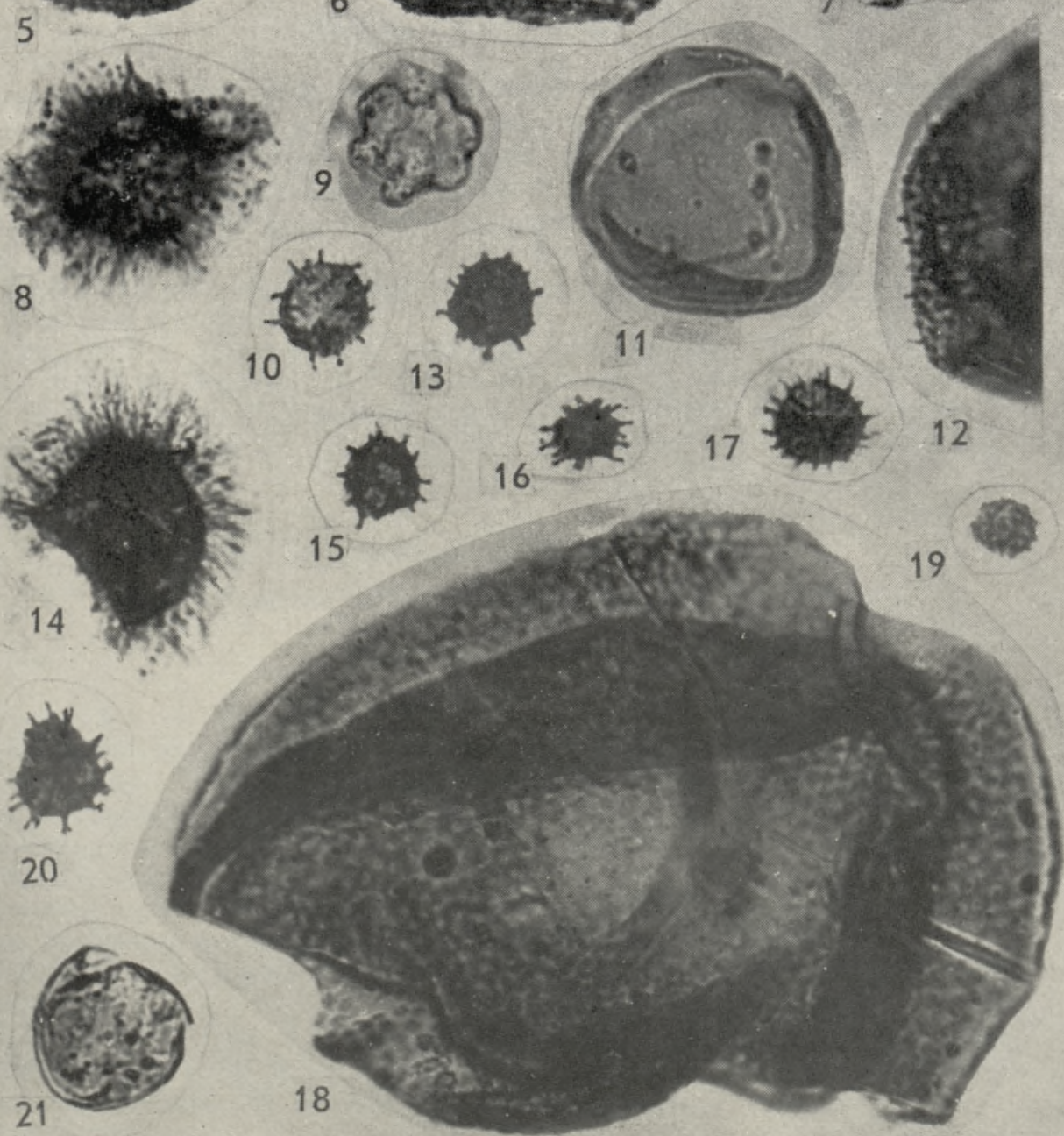

гаются вертикальные гребни, образующие пятиугольные ячейки. Общая форма оболочек близка к пятиугольнику. Диаметр оболочки $18-23 \mu \kappa$, высота гребней 2-4 мк, стенка очень тонкая (до 0,5 $м \kappa$ ), цвет от бледножелтого до прозрачного.

С равнение. От других видов отличается меньшими размерами, радиальной ориентировкой гребней и пятиугольным контуром.

Р аспространени е. Вергальский и раусвеский горизонты нижнего кембрия Прибалтики, реже - кибартайский горизонт.

М а те р и ал. Вергальский горизонт: р. Ижора, обн. у пос. Федоровский совхоз - 1 экз. Раусвеский горизонт: скв. Кибартай-22, гл. 1355 м3 экз.; скв. Селисте-173, гл. $493-489$ м- 3 экз., скв. Лудза-15, гл. $696 \mu-3$ экз. Кибартайский горизонт: скв. Гартждай-8, гл. $2036 \mu-$ 3 экз.

Подгруппа Sphaeromorphitae Downie, Evitt, Sarjeant, 1963

Род Leiosphaeridia Eisenack, 1958

Leiosphaeridia bicrura ${ }^{7}$ Jankauskas, sp. nov.

Таблица, фиг. 11, 21

Голоти п - экз. 398, препарат № 15-30-312/1; фиг. 11; ЛитССР, скв. Ячёнис-299, гл. 312 ж; нижний кембрий, раусвеский горизонт.

О пи с ание. Оболочка сферическая, диаметр $30-35$ мк, тонко- и гладкостенная, делящаяся надвое по прямсй ровной линии.

$\mathrm{C}$ р а н н н ие. От других лейосферидий отличается делимостью оболочек.

$\mathrm{P}$ a спространени е. Вергальский и раусвеский горизонты нижнего кембрия Прибалтики.

М а те ри ал. Вергальский горизонт: скв. Ячёнис-299, гл. 321 м 2 экз.; скв. Кибартай-22, гл. $1388-1383$ м - 16 экз.; скв. Стонишкяй, гл. $2109 \mu-3$ экз. Раусвеский горизонт: скв. Ячёнис-299, гл. $312 \mu-$ 8 экз.; скв. Селисте-173, гл. 493-481 м-3 экз.; скв. Лудза-15, гл. $696 м-3$ экз. и др.

\section{Род Lophominuscula Naumova, 1960}

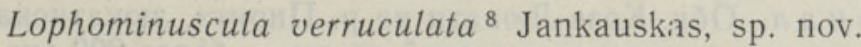

Таблица, фиг. 19

Голотип - экз. 403, препарат № 15-4-1383/6; фиг. 19; ЛитССР, скв. Кибартай-22, гл. 1383 м; нижний кембрий, вергальский горизонт.

О писание. Оболочка сферическая или слабо вытянутая, тонкостенная, покрыта относительно крупными полыми бугорками (вздутиями оболочки). Диаметр оболочки $5-7, \mu \kappa$, диаметр бугорков 0,5 мк, их высота $0,4-0,5$ мк.

С равнение. От наиболее близкого вида L. prima Naum. отличается крупными бугорками и часто несферической формой.

Р ас п р ост р а не н е. Вергальский горизонт нижнего кембрия Прибалтики.

М а тери ал. Скв. Кибартай-22, гл. 1388-1383 $м-22$ экз.; скв. Стонишкяй, гл. $2109 \mu-2$ экз.; скв. Саснава-6, гл. $1021-1024 \mu-$ 15 экз.; скв. Ячёнис- 299 , гл. $320-321$ м - 1 экз.

7 От bicrurus (лат.) - раздвоенный.

8 . От verruculatus (лат.) - мелкобородавчатый. 


\section{Род Microconcentrica Naumova, 1960}

Microconcentrica deimenica ${ }^{9}$ Jankauskas, sp. nov.

Таблица, фиг. 9

Голлотип - экз. 392, препарат № 15-4-329-В; фиг. 9; ЛитССР, скв. Кибартай-30, гл. 1268,5 ж; средний кембрий, дейменская серия.

О писание. Оболочка сферическая с крупноволнистым контуром, тонко- и гладкостенная, осложнена вздутиями поверхности наподобие крупных полусферических бугорков. Диаметр оболочки 15 мк, диаметр вздутий 5 мк, их высота 2 мк.

С ра внен ие. От других видов отличается крупными и малочисленными вздутиями.

Р аспространение. Дейменская серия среднего кембрия Прибалтики.

М а т е р и а л. Скв. Кибартай-30, гл. $1268,5 \mu-5$ экз.

\section{Род Tasmanites Newton, 1875}

Tasmanites piritaensis ${ }^{10}$ Posti et Jankauskas, sp. nov.

Таблица, фиг. 18

Голотип - экз. 402, препарат № 15-19-29-А, фиг. 18; ЭстССР, p. Пирита, обн. Козе-Люкати; нижний кембрий, какумягиская пачка тискреской свиты.

О п и сан ие. Оболочка толстостенная с мелковолнистым контуром, покрыта бугорками. От вершин бугорков отходят поры, пронизывающие стенки оболочки или слепо оканчивающиеся внутри ее. Диаметр оболочки $150-200 \mu \kappa$, толщина стенки оболочки $4-5$ мк, реже 2-3 мк, диаметр бугорков 2-3 $м \kappa$, высота $0,5-0,8$ мк. Расстояния между вершинами бугорков (между порами) $4-5$ мк. Диаметр пор до 0,3-0,4 мк.

С р а внени е. От близкого морфологического вида $T$. volkovae Kirjanov отличается расположением пор на вершинках бугорков, а не в промежутках между ними.

Р а сп р ост р анен и е. Люкатиский горизонт нижнего кембрия Прибалтики.

М а те р и а л. Обн. Козе-Люкати на р. Пирита, люкатиская свита 8 экз., какумягиская пачка тискреской свиты - более 200 экз.

\section{Л ИТЕРА Т У Р А}

Биркис А. П., Брангулис А. П., Волкова Н. А., Розанов А. Ю. 1970. Новые данные по стратиграфии кембрия Западной Латвии. Докл. АН СССР, 195 , № 4.

В олкова Н. А. 1968. Акритархи докембрийских и нижнекембрийских отложений Эстонии. В кн.: Проблематика пограничных слоев рифея и кембрия Русской платформы, Урала и Казахстана. Тр. Геол. ин-та АН СССР, вып. 188.

В ол ков а Н. А. 1973. Акритархи и корреляция венда и кембрия западной части Русской платформы. Советская геология, № 4.

У мнова Н. И., Фандер фли т Е. К. 1971. Комплексы акритарх кембрийских и нижнеордовикских отложений запада и северо-запада Русской платформы. В кн.: Палинологические исследования в Белоруссии и других районах СССР. Минск.

Фр идрихсоне А. 1971. Акритархи Baltisphaeridium и гистрихосферы (?) из кембрийских отложений Латвии. В кн.: Палеонтология и стратиграфия Прибалтики и Белоруссии. Вильнюс.

9 По дейменской серии.

10 По названию р. Пирита. 
Янкауска с Т. В. 1972. Биостратиграфия нижнего кембрия Литвы (по акритархам). Докл. АН СССР, 205, № 5.

Я нка уск а с Т., П ости Э. 1973. Микропалеонтологическая характеристика стратотипических разрезов нижнего кембрия Эстонии. Изв. АН ЭССР, Хим. Геол., 22, № 2 .

Янка уск а с Т. В. 1974. Корреляция кембрийских отложений Литовской ССР (по акритархам). В сб.: Биостратиграфия и палеонтология нижнего кембрия Европы и Северной Азии. М.

Литовский научно-исследовательский геологоразведочный институт

Поступила в редакцию

Институт геологии

Академии наук Эстонской ССР

17/II 1975

\section{T. JANKAUSKAS, Erika POSTI}

\section{BALTIKUMI KAMBRIUMI UUSI AKRITARHE}

Artiklis on kirjeldatud 10 uut Baltikumi alam- ja keskkambriumi akritarhi liiki. Nendest 4 liiki on iseloomulikud ainult ühele lademele: Tasmanites piritaensis lükati, Lophominuscula verruculata vergale, Micrhystridium oligum rausve ja Microconcentrica deimenica deimena lademele. Vergale ja rausve lademes esinevad Baltisphaeridium acerosum, B. strigosum, Micrhystridium heterospinosum, Cymatiosphaera capsulara, Leiosphaeridia bicrura, Cymatiosphaera radiata. Viimast liiki leidub ka kibartai lademes.

\section{T. JANKAUSKAS, Erika POSTI}

\section{NEW CAMBRIAN ACRITARCHS FROM THE EAST BALTIC AREA}

The authors present a description of 10 new species of Lower and Middle Cambrian acritarchs widely distributed in the East Baltic Area. Among others, they include species that occur only in one stage. They are: Tasmanites piritaensis (Lükati Stage), Lophominuscula verruculata (Vergale Stage), Micrhystridium oligum (Rausve Stage) and Microconcentrica deimenica (Deimena Stage). The others - Baltisphaeridium acerosum, B. strigosum, Micrhystridium heterospinosum, Cymatiosphaera capsulara, and Leiosphaeridia bicrura occur in the Vergale as well as in the Rausve stages, whereas the range of Cymatiosphaera radiata extends from the Vergale to the Kibartai Stage. 